\title{
PERSISTENCE, VAGUENESS, AND LOCATION
}

\author{
Antony Eagle \\ University of Adelaide, antonyeagle.org
}

Forthcoming in The Journal of Philosophy

I will discuss two arguments in favor of perdurance. The first is Sider's argument from vagueness. ${ }^{1}$ Sider regards this argument as "one of the most powerful" in favor of perdurantism. I make the observation - obvious once made, but I am unable to find it elsewhere in the literature that endurantists have principled grounds to claim that the argument is unsound (§§I-III). Having made this observation, I use it to emphasize a somewhat neglected difference between endurantists and perdurantists with respect to their views on material objects (§IV). These views, in the case of endurantists, lead to a further, less than conclusive but nevertheless interesting argument against endurantism - the anti-fundamentality argument - which I discuss in the second half of the paper $(\S \S \mathrm{V}-\mathrm{VI})$.

\section{THE ARGUMENT FROM VAGUENESS}

To begin, some terminology. An assignment is a (possibly partial) function from times to a set of entities existing at each time; a D-fusion of an assignment is an entity that is, at each time for

\footnotetext{
${ }^{1}$ Theodore Sider, Four-Dimensionalism: an Ontology of Persistence and Time (Oxford: Clarendon Press, 2001), at §4.9.3.
} 
which the assignment is defined, constituted by the fusion of the members of the set which is the value of the assignment at that time; a minimal D-fusion of an assignment is a D-fusion which exists only at the times for which the assignment is defined. ${ }^{2}$ In these terms, Sider's argument aims to establish this conclusion:

(U) “every assignment has a minimal D-fusion". 3

U swiftly entails the existence of temporal parts, because the singleton assignment $\{\langle t, x\rangle\}$ is wellformed for any $x$ existing at $t$, and so has a minimal D-fusion - an entity which is the fusion of $x$ at $t$ and exists only at $t$, which meets Sider's widely agreed criteria for being a temporal part of $x$ at $t^{4}$

Note how important the word 'minimal' is in U. If it is omitted, we have only this principle:

(U-) Every assignment has a D-fusion.

And U- can be true without the existence of temporal parts. The assignment $\{\langle t, x\rangle\}$ will simply have $x$ itself as its D-fusion, and that may well be an object which is not entirely restricted to $t-$ indeed, it could be an enduring object.

\footnotetext{
${ }^{2}$ I assume here a two-place atemporal parthood relation ' $x$ is part of $y$ ', which applies indifferently to material objects and regions of spacetime. It obeys at least the axioms of minimal extensional mereology: see pp. 25-31 of Peter Simons, Parts (Oxford: Clarendon Press, 1987). (The mereological structure of spacetime regions however is given by classical extensional mereology.) Sider's own formulation (ibid., $\S 9.2)$ makes use of a three place temporally-relativized parthood relation, ' $x$ is part of $y$ at $t$ ', for dialectical reasons; but since the sort of endurance I will define below makes use of an atemporal parthood relation, we need not get involved in the additional complexity of temporally relativized mereology.

${ }^{3}$ Ibid., at p. 138 .

${ }^{4}$ But see Kristie Miller, "Blocking The Path From Vagueness To Four Dimensionalism," Ratio, XVIII, 3 (September 2005): 317-331, esp. §3.
} 
Sider's argument for U adapts and advances Lewis' argument for the existence of fusions of arbitrary sets of objects - for the thesis of unrestricted composition. The argument involves these premises: ${ }^{5}$

(P1*) If minimal D-fusion were restricted, there would be two possible situations that could be smoothly and incrementally transformed into one another, giving rise to a continuous series of intermediate situations, such that a minimal D-fusion existed in one situation and a minimal D-fusion does not exist in the other.

(P2*) In no continuous series of cases representing a smooth and incremental transformation like that mentioned in premise $\mathrm{P} 1 *$ is there a sharp cutoff between cases where minimal D-fusion occurs and when it does not.

(P3*) In any situation, every minimal D-fusion either determinately exists or determinately fails to exist.

The actual argument is now straightforward. Minimal D-fusions must have sharp cutoffs between cases, by P3*; but if there were a continuous sequence of cases, there would fail to be sharp cutoffs, by P2*, so there can be no such continuous sequence of cases. But by contraposing P1*, we may derive from the non-existence of a continuous sequence of cases that minimal D-fusion cannot be restricted.

The argument is valid, so those who wish to reject temporal parts need to find fault with some premise. Sider appears to regard P3* as the most controversial; accordingly, he spends considerable effort defending P3*, arguing that if the existence of a minimal D-fusion could be a

\footnotetext{
${ }^{5}$ Sider, Four-Dimensionalism, op. cit., at p. 134 (lightly paraphrased).
} 
vague matter, then there would be objectionable indeterminacy in sentences in the pure language of first order logic with identity. Sider recognises that some may not be persuaded, so concludes that "anyone who accepts that logic is non-vague ... must also accept four-dimensionalism". ${ }^{6}$ I am happy to accept that logic is non-vague, and in turn accept P3*. But the other two premises are also subject to objections.

P2* has been objected to in a variety of ways. Sider's defense of it is that it would be "metaphysically arbitrary" to propose a sharp cutoff at any particular place in a continuous series. ${ }^{7}$ This notion of 'metaphysical arbitrariness' is playing a crucial role here, and one might well wonder, as Nolan does, ${ }^{8}$ whether it is able to support all that is demanded of it. In particular, Nolan develops a model on which it seems there can be metaphysically principled sharp cutoffs even when all the intuitive criteria involved are vague, ${ }^{9}$ as long as we do not expect to extract jointly necessary and sufficient conditions from the vague criteria. In another vein entirely, Balashov argues that $\mathrm{P} 2 *$ has counterexamples, because some assignments - which barely differ from others which have minimal D-fusions - have D-fusions which, if they were minimal, would violate physical conservation laws (such as the conservation of matter). ${ }^{10}$ Such minimal D-fusions would, he argues, "feature an object $A$ going out of existence at $t^{*}$ and popping back into existence ex nihilo". ${ }^{11}$ Balashov concludes that such minimal D-fusions would be physically impossible, so this minimal difference between the two assignments gives rise to a sharp cutoff in the existence of minimal D-fusions. I mention these objections to P2* only for completeness, and I will here accept that premise.

${ }^{6}$ Ibid., at p. 132 .

${ }^{7}$ Ibid., at p. 124.

${ }^{8}$ Daniel Nolan, "Vagueness, Multiplicity and Parts," Noûs, XL, 4 (December 2006): 717-37, §3.

${ }^{9}$ Ibid., $\$ 5$.

${ }^{10}$ Yuri Balashov, "On Vagueness, 4D and Diachronic Universalism," Australasian Journal of Philosophy, LXXXIII, 4 (December 2005): 523-31.

${ }^{11} \mathrm{Ibid}$., at p. 528. 
However, even granting $\mathrm{P} 2^{*}$ and $\mathrm{P} 3^{*}$, the argument can be resisted. For the remaining premise P1* may be rejected by endurantists on entirely principled grounds. This is because, if objects endure, there cannot be, in every situation in which there is a minimal D-fusion, a continuous series of situations between it and a situation in which there is no minimal D-fusion. To see why there will inevitably be a discontinuity, we need to state more precisely what endurantism is.

\section{ENDURANTISM}

Endurantism is the thesis that persisting objects are wholly present at every moment at which they exist. $^{12}$ There is in the literature a history of objections to endurance on the grounds that there is some problematic wooliness to this notion 'wholly present', which is only emphasized by common attempts to gloss it using a temporally-relativized parthood relation. ${ }^{13}$

We may sidestep both issues if we make use of locative notions in defining endurance in a spacetime framework: ${ }^{14}$

(Endurance) $x$ endures throughout some classical spacetime region $R$ iff $x$ is exactly located at every temporally unextended region $R_{t}$ within $R$ which is the intersection of $R$ with some moment of time $t .{ }^{15}$

\footnotetext{
${ }^{12}$ I neglect interesting issues about how to formulate relativistic endurance: see Ian Gibson and Oliver Pooley, "Relativistic Persistence," Philosophical Perspectives, XX (2006): 157-98.

${ }^{13}$ See Sider, Four-Dimensionalism, op. cit., pp. 63-8 for an overview of the difficulties.

${ }^{14}$ See also the discussion in $\S 1$ of Antony Eagle, "Multiple Location Defended," Philosophical Studies (forthcoming).

${ }^{15}$ That is, treating moments of time as maximal instantaneous regions of spacetime, an enduring object that entirely fills some region $R$ is exactly located at each time-slice of $R$. The mereological notions in this definition are used in defining $R_{t}$ as the intersection of two regions of spacetime, so no temporal relativization of the parthood relation is required.
} 
In addition to the mereological notion of an intersection (the maximal overlap between two regions), this definition of endurance makes use of the locative notion of exact location. A number of theories of location may be found in the literature that give some content to this notion, though unfortunately no terminology has become standard. ${ }^{16}$ For present purposes, the exact location relation may be glossed as follows: it is the relation that every object $x$ bears to any region of spacetime which is exactly the same shape and size as $x$, which $x$ fills up, and which $x$ is wholly contained within. An object is exactly located at any region which is like the object's "shadow in substantival space"17.

Many endurantists take exact location as a primitive. ${ }^{18}$ Almost all who take it to be primitive believe that it could be a one-many relation. Sider has argued that if it is a fundamental relation, then plausible recombination principles entail that it could be one-many. ${ }^{19}$ The foregoing gloss on the primitive was careful to keep open the idea that an object could have more than one exact location. The definition of endurance above thus involves multiple location: the enduring object persists in virtue of being wholly contained in lots of different times, which is to say that it is wholly contained within many disjoint times. To connect this definition with the standard presentation of endurance, let us define the relation of whole containment: an object is wholly contained in $R$ iff it is exactly located at a (perhaps improper) subregion of $R$. Since each $R_{t}$ is a

\footnotetext{
${ }^{16}$ See for example Roberto Casati and Achille C. Varzi, Parts and Places (Cambridge, MA: MIT Press, 1999); Hud Hudson, The Metaphysics of Hyperspace (Oxford: Clarendon Press, 2005); and Josh Parsons, "Theories of Location," in Dean W. Zimmerman, ed., Oxford Studies in Metaphysics, vol. III (Oxford: Oxford University Press, 2007), pp. 201-32. A useful overview may be found in Cody Gilmore, "Location and Mereology," in Edward N. Zalta, ed., The Stanford Encyclopedia of Philosophy (Fall 2014 Edition, http: //plato.stanford. edu/archives/fall2014/entries/location-mereology/).

17 Parsons, op. cit., at p. 203.

${ }^{18}$ Cody Gilmore, "Time-Travel, Coinciding Objects, and Persistence," in Dean W. Zimmerman, ed., Oxford Studies in Metaphysics, vol. III (Oxford: Oxford University Press, 2007), pp. 177-98; Peter van Inwagen, "Four-Dimensional Objects," Noûs, XXIV, 2 (1990): 245-55; and Kris McDaniel, "Extended Simples," Philosophical Studies, CXXXIII, 1 (March 2007): 131-41.

${ }^{19}$ Theodore Sider, "Parthood," Philosophical Review, CXVI, 1 (January 2007): 51-91, at p. 52.
} 
subregion of some $t$, an object endures throughout $R$ iff it is wholly contained in each time overlapping $R$.

We need not treat exact location as primitive, and whole containment as defined in terms of it.

We could attempt to define both using some other primitive, as for example in Parsons' framework: ${ }^{20}$

It's useful to make a distinction between being entirely located somewhere... and what is usually known as "being wholly located" [i.e., being wholly contained] somewhere. When I say that I am all in the office - that I am not stepping over the threshold or sticking an arm out of the window - there are two things I might mean. One is that I am entirely in the office...: that everywhere disjoint from the office is free of me. The other thing I might mean is that I am wholly in the office: that none of me is missing from the office; every part of me is in the office. ${ }^{21}$

More precisely, we can follow Parsons in considering the relation of weak location. An object $y$ is weakly located in $R$ if $y$ can be at least partly found in $R$ - if $R$ "is not completely free of" $y .{ }^{22}$ Weak location can be defined from exact location as follows: $x$ is weakly located in $R$ iff $x$ is exactly located at $S$ and $S$ overlaps $R$. But we could opt to take it as an alternative primitive. If we do, we may offer an alternative definition of containment: $x$ is wholly contained in a region $R$ iff for any $y$ that is part of $x, y$ is weakly located in $R .{ }^{23}$ Let us say that an object $x$ is pervasively wholly contained in $R$ iff it is wholly contained in $R$ and, moreover, $x$ is weakly located in every part of $R$ - no part of $R$ is wholly free of $x \cdot{ }^{24}$ Finally, let us say that an object $x$ is confined to $R$

\footnotetext{
${ }^{20}$ It is important to note an instance of the pervasive terminological confusion in the literature: Parsons uses 'exact location' to denote the region which is the fusion of all the exact locations; this is because he affirms the thesis of Functionality, that each located object has just one exact location.

${ }^{21}$ Parsons, op. cit., at p. 212.

${ }^{22} \mathrm{Ibid}$., at p. 203. See also Gilmore, "Location and Mereology," op. cit., at §2.

${ }^{23}$ That is, where '@。' denotes weak location and '드' denotes parthood, $x$ is wholly contained in $R$ iff $\forall y(y \sqsubseteq x \rightarrow y @ R)$.

${ }^{24}$ That is, $x$ is wholly contained in $R$ and pervades $R$, where $x$ pervades $R$ iff $\forall S(S \subseteq R \rightarrow x @ S)$.
} 
iff $x$ is in $R$, and $x$ is found in $S$ only if $S$ overlaps $R \cdot{ }^{25}$ An object is confined to a region it is in iff none of it can be found outside of that region; it is wholly contained in a region if all of it can be found inside that region. As Parsons observes in the quotation above, these two notions are logically distinct: an object could be wholly contained in a region without being confined to it. There is, in the pure theory of location, no logical or conceptual obstacle to an object being wholly contained in many disjoint regions, or being pervasively wholly contained in many disjoint regions. So, just like primitive exact location, pervasive whole location is also potentially a one-many relation between objects and regions.

In fact, pervasive whole location behaves very much like exact location: an object which is pervasively wholly contained in a region both fills the region and has all of its parts in that region. I propose that exact location closely approximates pervasive whole containment; this would at least give a reasonable gloss to 'exact location', as I am using it, for those who protest that they do not understand the primitive. (Note that not all primitivists about exact location will accept this gloss. ${ }^{26}$ ) I will henceforth set aside the issue of whether exact location or weak location is the appropriate primitive, and take exact location as the appropriate notion to use in formulating endurance. So formulated, endurance is not subject to any internal conceptual incoherence, given the foregoing; whatever difficulties there may be with endurance must have other sources. ${ }^{27}$

\footnotetext{
${ }^{25} x$ is confined to R iff $x @ R$ and $\forall S(x @ S \rightarrow \exists r(r \sqsubseteq R \wedge r \sqsubseteq S))$.

${ }^{26}$ For example, an object which is pervasively wholly contained in two regions $R_{1}$ and $R_{2}$ will also be pervasively wholly contained in their fusion $R_{1}+R_{2}$; as Parsons notes (op. cit., at fn. 10), Gilmore denies that an object which is exactly located at some regions must be exactly located at their fusion ("TimeTravel, Coinciding Objects, and Persistence," op. cit.). See also McDaniel, op. cit., at pp. 132-3 and Antony Eagle, "Location and Perdurance," in Dean W. Zimmerman, ed., Oxford Studies in Metaphysics, vol. v (Oxford: Oxford University Press, 2010), pp. 53-94.

${ }^{27}$ Contrary to the arguments of Shiva Kleinschmidt, "Multilocation and Mereology," Philosophical Perspectives XXV, 1 (December 2011): 253-276. Kleinschmidt gives examples in which, she suggests, multiple exact location violates basic axioms of minimal mereology. But her examples require the mereolocative principle that if $x$ is exactly located at a subregion of $y$ 's exact location, then $x$ is a proper part of
} 
The definition at the beginning of this section fits well with existing characterizations of endurance. Dau gives an explicitly locative account of endurantist on which "the entire [persisting] object is to be found at each instant that it exists", ${ }^{28}$ and van Inwagen considers a 2spatial-dimensional flatland object, and maintains that if that object persists throughout a temporally extended region $R$, “all... instantaneous slices of $R$ are occupied by the very same twodimensional object". ${ }^{29}$ That is to say, the object is multiply exactly located at each instantaneous slice of $R$. This definition also makes perfect sense of why the locution 'wholly present' should have been chosen to express endurantism: it really, literally, is the view that the whole of an object, all of its parts, is present at - by being wholly contained in - every moment at which it exists. It also fits well with how some opponents of endurantism have characterized it. ${ }^{30}$

Despite this, not all who wish to affiliate with endurantism will accept my definition. Some will reject the atemporal notion of parthood, as well as the not-unrelated use of locational primitive between objects and spacetime regions (rather than between objects, spatial regions, and times). The preference some endurantists show for temporally-relativized mereological and locative relations stems ultimately from their attempts to deal with puzzles about change. Such puzzles are not my concern in this paper. I concede that the present conception of endurance is perhaps best suited to capture the persistence of simple objects which cannot gain or lose parts, like fundamental particles, rather than complex objects. ${ }^{31}$

\footnotetext{
$y$; and that principle will not be correct if multiple-location endurance is possible. See Eagle, "Multiple Location Defended," op. cit.

${ }^{28}$ Paolo Dau, "Part-Time Objects," Midwest Studies in Philosophy, XI, 1 (September 1986): 450-74, at p. 464.

${ }^{29}$ Van Inwagen, op. cit., at p. 113.

${ }^{30}$ Stephen Barker and Phil Dowe, "Paradoxes of Multi-Location," Analysis, LXIII, 2 (April 2003): 106-14.

${ }^{31}$ The story this sort of endurantist tells about complex objects may resemble a sort of nihilism about material things, treating changing complexes as variably-constituted aggregates of simples. Or it may involve something like Fine's notion of "variable embodiment": Kit Fine, "Things and their Parts," Midwest Studies in Philosophy, XXIII, 1 (September 1999): 61-74.
} 
I am going to set these issues aside, for my interest is in seeing how at least some orthodox endurantists, who accept my definition, might resist the argument from vagueness to the existence of temporal parts. I will in what follows take 'is exactly located at' as the basic locative relation, one compatible with change of parts over time, albeit one that may be usefully approximated by pervasive whole containment.

\section{ENDURANTISM AND THE ARGUMENT FROM VAGUENESS}

We noted earlier that Sider's argument for perdurance turned crucially on the existence of minimal D-fusions, not just D-fusions. So let us grant for the sake of argument that U- is true: every assignment has a D-fusion. But even granting that, there is a principled and non-vague restriction on when an assignment has a minimal D-fusion. First, let us define a class of assignments:

(Saturation) An assignment $f$ is saturated iff

$$
\forall t \forall x\left(x \in f(t) \rightarrow \forall t^{\prime}\left(x \text { is wholly contained in } t^{\prime} \leftrightarrow x \in f\left(t^{\prime}\right)\right)\right) \text {. }
$$

Gloss: an assignment $f$ is saturated iff any object which $f$ assigns to a time is wholly contained in all and only times to which $f$ assigns it. Whether an assignment is saturated will depend on whether things can be wholly contained in multiple times. Suppose that the endurantist is right, and the way that ordinary objects persist is by being wholly contained in different times. Suppose in particular that I endure. The assignment $\{\langle$ now, me $\rangle\}$ is not saturated, since I am wholly located at times other than now. But the assignment $\{\langle t, m e\rangle: t \in T\}$ (where $T$ is the set of times overlapping the spacetime region I persist throughout) is saturated: any time at which I am wholly 
contained is such that the assignment is defined and assigns me to that time, and I am never assigned to any time at which I am not wholly present.

The notion of a minimal D-fusion looks like a technical one, but Sider argues that

the question of which assignments have minimal D-fusions is far from being remote and technical. Indeed, we can restate this question in the following woolly yet satisfying fashion: under what conditions do objects begin and cease to exist ${ }^{32}$

If the endurantist were to address that rephrased question, it is clear what they would say: objects exist at exactly those times in which they are wholly contained; and thus begin to exist when they are first wholly contained somewhere, and cease to exist when they are no longer wholly contained anywhere. Accordingly, they have a simple answer to Sider's original question:

(Answer) An assignment has a minimal D-fusion iff it is saturated.

With this answer in hand, we can quickly see that $\mathrm{P} 1$ * will be rejected by the endurantist. For the only non-logico-mathematical expression in the definition of saturation of an assignment is 'wholly contained'. Sider has argued that the logical vocabulary exhibits no vagueness, and I assume also that the set-theoretic machinery in the definition of assignment and saturation also do not contribute to vagueness in whether an assignment is saturated. So as long as 'wholly contained' is not vague, we will have offered a non-vague restriction on which assignments have minimal D-fusions, and accordingly there will not be a continuous series of cases which smoothly vary in the minimal-D-fusion-relevant respects between cases in which there is and is not minimal D-fusion. Every such series will have a sharp cutoff at precisely the point where the relevant assignment goes from being saturated to unsaturated (or vice versa). Ultimately, there are

${ }^{32}$ Sider, Four-Dimensionalism, op. cit., at pp. 133-4. 
sharp cutoffs between cases concerning those regions at which something is exactly located, and these give rise to discontinuities in the saturatedness of a given assignment between arbitrarily close cases in other relevant respects. I characterize this as a denial of $\mathrm{P} 1 *$, because any series of situations between one in which an assignment has minimal D-fusion, and one in which it does not, will somewhere exemplify a sharp discontinuity in the exemplification of saturatedness by the assignment.

\section{EXACT LOCATION IS PRECISE}

The remaining question is whether 'wholly contained' is vague, undermining the above argument against the existence of continuous series of the sort Sider needs for the truth of premise P1*. Initially, it seems not. Recall the definition from $\S \mathrm{II}: x$ is wholly contained in $R$ iff there exists an $S$ such that $x$ is exactly located at $S$ and $S$ is a subregion of $R$. Assuming again that the logical vocabulary is not vague, the only candidate sources of vagueness are the exact location ascription, and the subregion ascription.

The subregion relation is a perfectly precise mereological relation between regions of spacetime. If desired, we could treat the mereology of classical spacetime regions as part of set-theory, identifying regions with their underlying point sets and 'is a subregion of' to be 'is a subset of', which would ensure that subregion is as non-vague as the remainder of the mathematical vocabulary used in the definition. ${ }^{33}$

\footnotetext{
${ }^{33}$ Even those who regard mereology as potentially vague, because it could be indeterminate when something is part of something else, should not think the mereology of regions ever exhibits this indeterminacy.
} 
Even if some subregionhood ascriptions ' $\alpha$ is a subregion of $\beta$ ' are vague, due to indeterminacy in the singular terms, it looks implausible to say that there can be vagueness due to imprecision in 'is a subregion of' itself. (The vagueness of 'the Simpson Desert is a subregion of the outback' is due entirely to indeterminacy in those location denoting expressions; if we could establish which precise regions the prima facie locative terms 'the Simpson Desert' and 'the outback' denoted, there would be no residual vagueness in whether or not the one was a subregion of the other.) Likewise, some exact location ascriptions are vague because of vagueness in the terms flanking the relational predicate. Consider Mt Kosciusko, and consider some marginal rock, neither clearly part of Mt Kosciusko, nor clearly not part of it. It might be thought, accordingly, that the location of Mt Kosciusko neither clearly includes nor clearly excludes the region the rock is exactly located at, ${ }^{34}$ and therefore that the location of Mt Kosciusko is not precise. This might be thought to provide some grounds for thinking that the location relation is a potential source of vagueness. Such cases are more closely related to Unger's "problem of the many" than to traditional problems of vagueness. ${ }^{35}$ There is no precise aggregate of rock which is the determinate referent of 'Mt Kosciusko', and it is that indeterminacy which prevents Mt Kosciusko from having a precise location. That the problem is due to the indeterminacy in the singular term, rather than any vagueness in the exact location relation, can be seen if we imagine a perfectly precise term referring to some particular aggregate of rock in the vicinity of Mt Kosciusko; that aggregate is exactly located at an equally precise region. Eliminating indeterminacy in the singular terms removes vagueness in the location ascription. (Assuming, along with most commentators, that such cases involve semantic indeterminacy rather than "ontic" vagueness.)

\footnotetext{
${ }^{34}$ Assuming again that if $x$ is part of $y$ then an exact location of $x$ is a subregion of an exact location of $y$.

${ }^{35}$ Peter Unger, "The Problem of the Many," Midwest Studies in Philosophy, v (1980): 411-67.
} 
Whether we can eliminate or manage this sort of indeterminacy in ordinary singular terms is an interesting question. But it is a question that need not be addressed in arguing that our Answer to Sider's question is a precise one. For Sider's premise P1* involves the idea of a sequence of cases, and the problem of vague singular terms strikes not in the construction of the sequence, but in the specification of particular cases. If we use terms that are susceptible to indeterminacy in specifying our cases, like 'Mt Kosciusko', then we apparently do not manage to pick out any determinate situations at all, since many very similar cases which differ in their most precise details are equally legitimate precisifications of the content of our descriptions. If we attempt to accurately specify a particular case, specifying in every detail the distribution and character of objects over regions of spacetime, we will be obliged to eschew familiar singular terms in favor of precise substitutes denoting particular regions and aggregates of matter. So efforts to construct a continuous series of cases that meets Sider's specifications will not be subject to vagueness arising from indeterminacy of denotation.

The key question remains: whether ascriptions of exact location are vague because of vagueness in 'is exactly located at'. One is tempted initially to respond: "how could exact location be vague?" But this is terminology, and we should be initially open to the possibility that our primitive location relation might be indeterminate - that for some precise object and precise region, it might be indeterminate whether the object is exactly located at that region. The likeliest prospect of this arises on some (but not all) interpretations of quantum mechanics.

In textbook treatments of quantum mechanics, a number of pairs of observables are linked by uncertainty relations: the more precisely we measure of one member of the pair, the more 
imprecise is the best measurement of the other member. ${ }^{36}$ Position and momentum are linked in this way. On the Copenhagen interpretation, the explanation of uncertainty relations between observables is that they are (in Bohr's terminology) complementary: the observables cannot be simultaneously measured because the underlying quantum mechanical state (the wavefunction) cannot simultaneously constitute both a perfectly precise state of position and a perfectly precise state of momentum. When a particle is in a precise state of momentum, on this view, it has no precise position at all, despite being a material object and being in space. But if a particle has no determinate position, there is no region at which it is exactly located. It might then be that ' $\alpha$ is exactly located at $\Gamma^{\prime}$ might be indeterminate, even when the singular terms ' $\alpha$ ' and ' $\Gamma$ ' are precise. And whether or not quantum indeterminacy of location can be parlayed into a continuous series of the sort needed by Sider's construction, there is considerable discomfort involved in reconciling a fundamental physical theory on which material objects need have no precise location with a fundamental ontology according to which objects begin and cease to be just when they begin and cease to be exactly located somewhere.

If the endurantist is to avail themselves of the response to Sider sketched above, they will have to endorse some alternative interpretation of quantum mechanics. Happily enough, the emerging consensus is that these sorts of textbook treatments of quantum mechanics are "profoundly unsatisfactory" because of the indefensible treatment of the process of measurement as involving the "collapse of the wavefunction" onto one particular observable. ${ }^{37}$ At least two of the philosophical defensible alternatives offer a treatment of exact location which ought to be palatable to the locative endurantist.

\footnotetext{
${ }^{36}$ David Z Albert, Quantum Mechanics and Experience (Cambridge, MA: Harvard University Press, 1992), ch. 2.

${ }^{37}$ David Wallace, "A Prolegomenon to the Ontology of the Everett Interpretation," in Alyssa Ney and David Z Albert, eds., The Wave Function: Essays of the Metaphysics of Quantum Mechanics (New York: Oxford University Press, 2013), pp. 203-222, at p. 209.
} 
- The first alternative is some "hidden variable" theory, which claims that the wavefunction needs to be supplemented with some further properties in order to specify the complete state of a given physical system. The canonical example is Bohm's theory, which recovers the predictions of orthodox quantum mechanics by supplementing the wavefunction with a complete specification of the exact locations of all material particles, where each particle has a precise exact location at every time. ${ }^{38}$ Obviously such a theory is amenable to an endurantist treatment according to which enduring particles are multiply located at different times.

- The second alternative is some kind of pure quantum theory, according to which the deterministic collapse-free evolution of the wavefunction is a complete story of the evolution of a physical system over time. On such a theory, what look like states of indeterminate location end up being reinterpreted. According to the Everett interpretation, ${ }^{39}$ a quantum state suggesting indeterminate location in fact is to be understood as involving a multiplicity of exact locations - an object is exactly located in one region on one "branch" of reality, and in a different region on another branch, but each branch is perfectly precise. The branch ontology, and indeed the ontology of ordinary continuants, is non-fundamental, but the persistence of such non-fundamental entities can be covered by a straightforward extension of endurance to involve multiple location at space-time-branch regions. ${ }^{40}$

\footnotetext{
${ }^{38}$ Sheldon Goldstein, "Bohmian Mechanics," in Edward N Zalta, ed., The Stanford Encyclopedia of Philosophy (Spring 2013 edition) http://plato.stanford.edu/archives/spr2013/entries/qm-bohm/; Albert, Quantum Mechanics and Experience, op. cit., ch. 7.

${ }^{39}$ Wallace, op. cit.

${ }^{40}$ Another pure no-collapse theory is so-called "wavefunction realism", according to which the real state of a system is given by the wavefunction's position in a very high-dimensional space. On such a view, it is not familiar objects which are exactly located; nevertheless, there is nothing indeterminate about the location of the wavefunction in its space. See David Z Albert, "Elementary Quantum Metaphysics," in J T Cushing, A Fine, and S Goldstein, eds., Bohmian Mechanics and Quantum Theory: An Appraisal (Dordrecht: Kluwer,
} 
Ultimately, the foundations of quantum mechanics remain murky, and it would be premature to take any theory of quantum phenomena as telling us whether or not location is precise. But it is suggestive that almost all of the current philosophically defensible approaches to quantum mechanics are entirely compatible with definiteness in the exact locations of ordinary continuants.

The foregoing considerations undermine the argument from quantum theory for vague location.

But there is also a positive reason for thinking exact location must be precise. In classical settings, endurantists ought to regard exact location as a fundamental relation. ${ }^{41}$ If there is no indeterminacy or vagueness in fundamental relations, ${ }^{42}$ then if exact location is fundamental, it will not be vague. Assuming that there is no ontic vagueness, the thesis that the fundamental is not vague is extremely attractive. (Vagueness then arises from some indeterminacy in how the truth values of non-fundamental sentences are fixed by the fundamental facts.) Given this thesis, if we can establish the fundamentality of endurantist location, then we have given endurantists a precise restriction on minimal D-fusion, and a principled reason to reject Sider's argument.

The distinction between fundamental and non-fundamental properties and relations is tricky to pin down precisely, but one non-negotiable feature is that the facts about the fundamental properties and relations should be complete, in the sense that all other facts about properties and relations should depend on, or be explained by, the body of facts concerning the fundamental properties and relations. Sider, speaking of the category of the fundamental more generally, characterizes completeness like this:

1996), pp. 277-284; and Jill North, "The Structure of a Quantum World," in Ney and Albert, eds., op. cit., pp. 184-202.

${ }^{41}$ This obviously gives this sort of endurantist a reason to favor a theory like Bohmian mechanics, which gives a fundamental role to particle location - and retains a familiar picture of particles as more or less ordinary continuants - when extending their treatment of persistence to the quantum realm. A version of the Everett interpretation which takes the branch structure to be fundamental may also be suitable; see Alastair Wilson, "Macroscopic Ontology in Everettian Quantum Mechanics," Philosophical Quarterly, LXI, 243 (April 2011): 363-382.

42 Theodore Sider, Writing the Book of the World (Oxford: Clarendon Press, 2012), at p. 137. 
Every non-fundamental truth holds in virtue of some fundamental truth... A fundamental truth (or fact) intuitively, is a metaphysically basic or rock-bottom truth (fact). Facts about the positions of subatomic particles would be, on most views, fundamental facts, whereas the fact that some people smile when they eat candy would presumably not be. ${ }^{43}$

The general idea is that there is a body of fundamental facts, the description of which is a complete specification of how things are, even though not every fact about how things are is explicitly included in the fundamental facts. The body of actual fundamental facts is sufficient to capture the actual possibility; similarly, other non-actual possibilities are completely specified by a body of possible fundamental facts that concern a given way things could be. If there are fundamental facts about the instantiation or distribution of a property or relation, then that property or relation is a fundamental relation. The case that location is a fundamental relation then rests on the claim that a complete basic specification of a possibility involves, unavoidably, facts about the locations of objects. (That is: location is a fundamental relation, and is also distinct from other fundamental relations, such as identity.)

Sider's example of a fundamental fact involves exact location, and many others agree that exact location is fundamental. ${ }^{44}$ But endurantists can offer an argument to bolster this common intuition. Namely, that if we do not make use of exact location, we would be unable to distinguish some possibilities which the endurantist regards as distinct. Accordingly, a body of propositions which excluded propositions about locations could not be a complete specification of a possibility, so it is a necessary condition on a body of facts being complete that it include some facts concerning exact location. From the account of fundamentality above, this would entail that exact location is a fundamental relation.

\footnotetext{
${ }^{43}$ Ibid., at p. 105.

${ }^{44}$ See McDaniel, op. cit., at p. 132 and Raúl Saucedo, "Parthood and Location," in Karen Bennett and Dean W. Zimmerman, eds., Oxford Studies in Metaphysics, vol. vI (Oxford: Oxford University Press, 2011), pp. $225-85$, at pp. 271-3.
} 
Consider some putatively complete specification of a possibility that does not include any facts about exact location. An austere version of this could involve something like Lewis' Humean supervenience,

The doctrine that all there is to the world is a vast mosaic of local matters of particular fact, just one little thing and then another.... We have geometry: a system of external relations of spatiotemporal distance between points. ... And at those points we have local qualities: perfectly natural intrinsic properties which need nothing bigger than a point at which to be instantiated. For short: we have an arrangement of qualities. And that is all. ${ }^{45}$

A Humean specification will tell us what the structure of space and time are like, in particular, what regions of space and time there are and their mereological structure. And it will tell us, of each region, what the fundamental qualitative character of the world at that region happens to be. ${ }^{46}$ Lewis gives an argument in his postscript B to "Survival and Identity" that such a specification would be complete. ${ }^{47}$ He argues there, in effect, that there could be a situation qualitatively indistinguishable from our own in the distribution of fundamental properties in which objects perdure (persist by having different temporal parts at each moment at which they exist), and concludes, via an invocation of Humean supervenience, that our world is one in which objects perdure. Material objects are claimed to be non-fundamental in this story, since the distribution of qualities to regions, plus classical mereology, suffices to determine which regions are occupied by material objects and what the identity conditions of those objects are. (Whether a perdurantist ought to accept this claim is the subject of §VI below.)

\footnotetext{
${ }^{45}$ David Lewis, Philosophical Papers, vol. II (Oxford: Oxford University Press, 1986), at pp. ix-x.

${ }^{46}$ In light of issues to do with quantum non-separability, we may need to include irreducible properties of regions. See Tim Maudlin, "Why Be Humean?," in his The Metaphysics Within Physics (Oxford: Oxford University Press, 2007), pp. 50-77.

${ }^{47}$ David Lewis, "Survival and Identity," in his Philosophical Papers, vol. I (Oxford: Oxford University Press, 1983), pp. 55-77, at pp. 76-7.
} 
The endurantist, of sort considered here, will most naturally resist this argument by rejecting Humean supervenience. Two situations could agree perfectly on the pattern of instantiation of properties at regions and yet be distinct possibilities, because they could differ in which objects possessed which properties. Suppose a situation contains a temporally extended spacetime region that exemplifies fundamental properties which collectively suffice for that region to contain an electron at each moment intersecting it. For all that has been said so far, this situation might involve an electron that persists throughout the region by being multiply exactly located at each timeslice of the region; or it might involve more than one electron that collectively fill the region by succeeding one another over time. It is clear that no endurantist will think these two situations are merely notational variants of one another. ${ }^{48}$ These are at least two distinct possible persistence scenarios consistent with the same distribution of qualities. Nothing we say about the qualitative character of the region will entail the facts about the pattern of exact location in this possibility. To distinguish these two different possibilities, however, it is sufficient to supplement the facts about the distribution of qualities with (i) a domain of objects, and (ii) a body of facts specifying the exact locations of each object in the domain. Such supplementary facts also suffice to help in the more general case of persistence through change, when an object changes from being $F$ to lacking $F$ iff it is exactly located at a region exemplifying $F$-ness and also exactly located at a subsequent region which not does exemplify $F$-ness. In this way, the endurantist can tell a complete story about various possible patterns of persistence by which things there are, where they are, and what they are like there.

\footnotetext{
${ }^{48}$ That is not to say that endurantists will regard the second situation as a live epistemic possibility, for the theoretical virtue of simplicity may encourage us to reject the second situation as needlessly complex compared to the postulation of a single continuant. But it is clear that endurantists will regard this use of Occam's razor as ruling out a genuine metaphysical possibility.
} 
The foregoing provides reasons for endurantists to distinguish certain possibilities, and argues that facts about exact location would enable them to do so. To establish that facts about exact location are fundamental, we need the additional premise that no better candidate species of supplemental fact exists. It is difficult to provide a general argument in support of this premise; who knows what sort of fundamental grounds could be provided that would suffice to fix the endurantistically important facts? But one interesting rival is the theory which takes as fundamental a domain of objects, along those facts expressed by predications of the form ' $x$ is $F$ at $R{ }^{, 49}$ Such a theory of region-relative predication, and the conception of properties as relations to regions, has been used to respond to puzzles of intrinsic change for endurantism of the sort considered here. If we say that, strictly speaking, an object has a property at a region only if it is exactly located there, then the facts about exact location can be derived from region-relative predications, which will also entail facts about which properties are exemplified by which objects, and where.

This alternative candidate for a fundamental relation seems to me to have the fatal flaw that it does not actually manage to provide a complete specification of a possibility. For there are properties exemplified at regions at which nothing is exactly located. For instance, a magnetic field may have field values at empty regions of spacetime that do not fall within the exact location of any object. Or, a propos our earlier discussion, the "pilot wave" that influences particle motion in Bohmian mechanics has values everywhere in spacetime without there being a plenum of particles. Neither taking magnetic fields to be ghostly material objects which pervade spacetime, nor claiming that regions can have properties at themselves, look at all plausible. It is much more

\footnotetext{
${ }^{49}$ Van Inwagen, op. cit., at p. 250; Gilmore, "Location and Mereology," op. cit., at $§ 6.6$. Note that we can reconstruct such facts in the fundamental location framework: $x$ is $F$ at $R$ iff $x$ is exactly located at $R$ and $R$ instantiates $F$.
} 
natural to take fields to be grounded simply in the instantiation of certain qualities throughout a certain region.

Even if this problem could be overcome in some non-clunky way, the theory that exact location is fundamental avoids one objection commonly pressed against region-relative predication, the problem of temporary intrinsics. ${ }^{50}$ Lewis' objection is simply that some properties are not relational and are had simpliciter. The fundamental location approach respects this intuition: properties are exemplified at regions, and are not had relative to anything. Objects have properties in virtue of being located at regions with those properties; change in properties is variation in what the locations are like. ${ }^{51}$

Assuming that the fundamental relations are exact location and the exemplification of qualities by regions also strikes me as more elegant than the region-relative predication theory. We need, for other reasons, regions to exemplify properties: in particular, having shapes, having certain distributions of electro-magnetic and other fields, etc. At least the objects that are exactly located at those regions - notably, shape, inherit some of these properties of regions. ${ }^{52}$ To take this to be the model of all property instantiation is neater than proposing that some properties are basically had by regions, and some basically had by objects.

I conclude that endurantists have reason to distinguish certain possibilities; that taking exact location to be fundamental allows them to do so; and that exact location is a more attractive candidate fundamental relation than the most popular alternative.

\footnotetext{
${ }^{50}$ David Lewis, On the Plurality of Worlds (Oxford: Blackwell, 1986), at pp. 202-4.

${ }^{51}$ This approach, incidentally, solves the somewhat neglected puzzle of why it is that one and the same enduring object can appear so different at different locations, the answer being that the regions have different qualities, the object inheriting them from its locations.

${ }^{52}$ McDaniel, op. cit.; Bradford Skow, “Are shapes intrinsic?” Philosophical Studies, CXXXIII, 1 (March 2007): 111-30.
} 


\section{THE ANTI-FUNDAMENTALITY ARGUMENT}

The fundamentality of exact location has at least one further useful consequence for endurantists.

For, in conjunction with the premise that fundamental relations are recombinable, the fundamentality of exact location entails the possibility of extended simples:

The possibility of extended simples follows from plausible principles about location and possibility; mereology has nothing to do with it. The principle about location is that [exact] location is a fundamental relation between objects and points of space. The principle about possibility is a combinatorial principle requiring, roughly, that any pattern of instantiation of a fundamental relation be possible. These principles imply the possibility of the location relation's holding in a onemany pattern between a mereologically simple object and points of space - an extended simple. ${ }^{53}$

The possibility of extended simples is important for endurantists, because it demonstrates the metaphysical possibility - and not merely the conceptual coherence - of something persisting by enduring. Enduring objects lack temporal parts, and are temporally simple. Yet they are extended, in the sense that they manage to fill a temporally extended region. This argument shows that there is no tension between lacking temporal parts and having positive temporal extent, as long as enduring entities are (temporally) extended simples. In effect, the recombination argument supports the conception of endurance as temporal multi-location; to that extent, endurantists of this stripe have reason to accept the fundamentality of exact location because it is needed for this recombination argument.

A similar application of recombination can also be used to establish that exact location is manyone. That is, many material objects can be exactly located at the same region. One sort of situation demonstrating this possibility involves interpenetration, where two material substances

${ }^{53}$ Sider, "Parthood," op. cit., at p. 52. 
occupy the same place without being constituted of the same stuff, as when a ghost interpenetrates a wall through which it passes. Another involves coincidence. Take Gibbard's case of a statue and a lump of clay that constitutes it,${ }^{54}$ and assume they are exactly co-located throughout both of their lives. Though their actual spatiotemporal careers overlap perfectly, the modal differences in what their careers could have been ensure the possibility of distinctness, and thus the actuality of distinctness. The puzzle is: assuming they are actually distinct, what grounds their distinctness? ${ }^{55}$ The literature on this puzzle is vast, and here I only wish to point out that endurantists who are tempted to think that the statue and the lump are distinct - and many are have a straightforward story to tell if the foregoing is correct: they are distinct because it is a fundamental fact that both the statue and the lump are included in the domain; they are coincident because it is another fundamental fact that they are exactly located at the same region. By contrast, the Humean story of what is fundamental cannot properly ground the existence of distinct coincident entities, because they share all their non-modal features at their location. This is why perdurantists instead explain away the appearance of distinctness, tying to use the pragmatics of possibility sentences to explain why it seems there might be a case of coincidence (in effect, that using the word 'statue' rather than 'lump' triggers different possibility judgements, despite the identity of the entities denoted by 'the statue' and 'the lump').

Yet one might be concerned that the principle of recombination is too powerful. For it generates not only the possibility of extended simples and coincident entities, but also other possibilities that may strike us as stretching the bounds of credulity. Say that a material object $x$ is a proper contraction of material object $y$ iff at least one of $x$ 's exact locations is a proper subregion of $y$ 's

\footnotetext{
${ }^{54}$ Allan Gibbard, “Contingent Identity,” Journal of Philosophical Logic, IV, 2 (May 1975): 187221.

${ }^{55}$ Karen Bennett, "Spatio-Temporal Coincidence and the Grounding Problem," Philosophical Studies, CXVIII, 3 (April 2004): 339-371.
} 
exact location. Using this terminology, Saucedo ${ }^{56}$ argues that the principle of recombination, when applied to the exact location relation, entails the possibility of some unusual entities: (i) crowded simples, objects which have no parts, but which do have proper contractions (all extended simples are crowded simples, but not vice versa); and (ii) compact fusions, which have parts, but no proper contractions:

Compact fusions may thus be arbitrarily small; their location may even be a mereologically simple region, e.g., a point. Nonetheless, they have proper parts. In fact, their proper parts may be arbitrarily large - they may even be proper contractions of one of their proper parts. ${ }^{57}$

In outline, his argument is straightforward. ${ }^{58}$ The principle of recombination states that any distribution of distinct fundamental relations that comes from combining previously existing possibilities is itself metaphysically possible. There is a possibility $u$ in which there are distinct objects $a$ and $b$ such that $a$ is exactly located at $R$ and $b$ is exactly located at $S$, where $R \neq S$. There is also a possibility $v$ in which $a$ is a proper part of $b$ and $S$ is a proper subregion of $R$. Since our specification of $u$ mentioned nothing about parthood, and the specification of $v$ mentioned nothing about location, the following scenario $w$ is conceptually consistent: a scenario which conjoins the locative aspects of $u$ with the mereological aspects of $v$. But since location is a fundamental relation, and is conceptually and metaphysically distinct from the fundamental mereological relation of parthood (which is needed independently of any facts about material objects to provide mereological structure on spacetime), recombination entails that $w$ is a genuine metaphysical possibility. But in $w, b$ is a proper contraction of one of its own proper parts: $b$ is a compact fusion.

\footnotetext{
${ }^{56}$ Saucedo, op. cit., $\S 6$.

${ }^{57}$ Ibid., at p. 279.

${ }^{58} \mathrm{Ibid}$., at p. 262. I have omitted some complications that make things unnecessarily obscure for my purposes.
} 
Saucedo concedes that the possibility of such "tiny monsters" is "bizarre". If compact fusions are possible, then it will not necessarily be true that an object is wherever its parts are exactly located, even though this principle is defended by Parsons ${ }^{59}$ as an apparent conceptual truth, and by Sider $^{60}$ as a principle that "everyone accepts" about parthood. (It is closely related to one of the basic facts about exact location McDaniel offers in glossing it - though he uses the term 'occupation' - that "if an object $x$ occupies a region of spacetime $r$, then, typically, every part of $x$ occupies some part of $r "{ }^{61}$ ) If crowded simples are possible, we get similarly bizarre possibilities. The fundamentality of parthood and location together permit in fact almost any sort of fantastic misalignment between the mereological and locational structure of spacetime and its occupants.

The oddity of these sorts of entities should give us pause in uncritically accepting the application of recombination, which provides our only real motivation for accepting them. In turn, the use of recombination is only possible if exact location is a fundamental relation. Taken together, these observations suggest another argument against endurantism; call it the anti-fundamentality argument:

(AF1) The metaphysical possibility of extended simples (but also compact fusions, crowded simples, etc.,) follows from AF2, the fundamentality of exact location, and the distinctness of exact location from parthood.

(AF2) Recombination does generate metaphysical possibilities when what are recombined are facts about the distribution of distinct fundamental relations.

\footnotetext{
${ }^{59}$ Parsons, op. cit., at p. 213.

${ }^{60}$ Sider, "Parthood," op. cit., at p. 75.

${ }^{61}$ McDaniel, op. cit., at p. 132.
} 
(AF3) Crowded simples, compact fusions, etc., are metaphysically impossible.

(AFC1) Therefore, either the exact location relation is not fundamental, or it is not distinct from parthood.

(AF4) If endurantism is correct, the exact location relation is fundamental and distinct from other fundamental relations.

(AFC2)Therefore, endurantism is not correct.

This argument is propositionally valid. The outline of the argument for AF1 was given earlier in this section. ${ }^{62}$ Earlier, I argued that it is desirable for endurantists to endorse the fundamentality of exact location, both to resist Sider's argument and to respond to Lewis's argument for perdurantism. The model for fundamental location in the previous section makes parthood fundamental. And the desirability for endurantists to endorse the possibility of coincidence ensures that parthood and location are distinct. ${ }^{63}$ Collectively, these support AF4. So the two premises needing additional support are AF2 and AF3.

\footnotetext{
${ }^{62}$ Note that the application of recombination needs some antecedent possibilities, and one might deny those antecedent possibilities. For example, a nihilist denies that any material objects have proper parts: it is not after all possible that $a$ be a proper part of $b$. See Cian Dorr, The Simplicity of Everything, PhD thesis (Princeton, NJ: Princeton University, 2002); and Theodore Sider, "Against Parthood," in Karen Bennett and Dean W. Zimmerman, eds., Oxford Studies in Metaphysics, vol. VIII (Oxford: Oxford University Press, 2013), pp. 237-293.

${ }^{63}$ The sort of objection I am envisaging, which is blocked by this observation, is a denial that mereological relations on objects - as opposed to on regions - are fundamental. Perhaps - the objector maintains - when restricted to terms $x, y$ denoting material objects, ' $x$ is part of $y$ ' is to be glossed: $x$ is exactly located at $R$ and $y$ is exactly located at $S$ and $R$ is part of $S$. This proposal, however, is incompatible with the possibility of interpenetration, where we might have spatial overlap without parthood; and also incompatible with standard takes on coincidence, where the coincident entities have exactly the same location, that location is trivially an improper part of itself, but the coincident entities are not parts of each other. We cannot reduce material parthood to exact location and regional parthood if we wish to endorse the possibility of coincidence, as endurantists tend to want to do.
} 
Combinatorial principles about possibility are generally attractive. ${ }^{64}$ The idea that, somehow, at least some new possibilities can be constructed by rearrangement of the constituents of old possibilities is uncontroversial. We make use of such principles in an uncritical fashion in almost all of our modal epistemology, for we come to know about new possibilities in large part by recombining the actual properties and individuals of this world in new ways, and that would only generate knowledge if such recombination was in fact sufficient for the resulting rearrangement to be possible. So it is both attractive and epistemically unavoidable to endorse some principle of limited recombination. The difficult task is to make clear just how recombination is to be restricted to ensure that rearrangement of actuality in accordance with that principle really is sufficient for possibility.

The weaker the recombination principle involved, the easier it is to accept that employing it does generate genuine possibilities. The principle employed above is weak, since the additional premises needed to apply it correctly - that one is recombining previously given possibilities for the distribution of distinct fundamental relations - are quite strong. If one was convinced that one fundamental relation was neither analyzable in terms of, nor reducible to, or supervenient on, another fundamental relation, nor vice versa, then those relations would be metaphysically independent of one another. Given this, any consistent specification of how these independent relations were instantiated would describe a metaphysical possibility, for we would have ruled out antecedently just the kinds of confounding factors which normally block the move from consistency to possibility.

\footnotetext{
${ }^{64}$ We need not accept combinatorialism about modality to accept that a scenario's following from suitably restricted recombination is sufficient for its possibility. See D M Armstrong, A Combinatorial Theory of Possibility (Cambridge: Cambridge University Press, 1989).
} 
Saucedo offers a direct argument from metaphysical parity for recombination. ${ }^{65}$ His argument, roughly, is this: it would be metaphysically arbitrary to allow that some recombinations of independent fundamental relations are possible, but others are not. ${ }^{66}$ All the fundamental relations are on a par. But some recombinations of independent fundamental relations are possible, for otherwise it would turn out that "many arguably contingent features of the actual world [such as the number of concrete objects] are necessary". So all recombinations of independent fundamental relations are possible. The determined objector could find places to object to this argument; rather than do so, I regard it as more plausible at this point to accept the recombination principle in question. As Sider says, "everyone should admit some combinatorial element to possibility, and it seems likely that that element will be enough for the argument for extended simples", ${ }^{67}$ and that is also enough for the possibilities mentioned in AF1. Note too that blanket restrictions on recombination will also exclude arguments for the possibility of extended simples and coincidence, possibilities that the typical endurantists finds theoretically congenial.

What can be said in favor of AF3? I have already made some observations that are germane: that the possibility of the entities mentioned in AF3 would violate widely accepted and apparently true principles about parthood, location, and coincidence. I do not wish to elevate these principles to the status of non-negotiable platitudes. But their prima facie plausibility is reason for considerable suspicion about the possibility of situations which violate them. Moreover, remember the dialectic: the critic of AF3, given the truth of the other premises, is a defender of endurance. Endurance is often contrasted, by its defenders, with the "crazy metaphysic" of perdurantism - that the correct theory of persistence should cohere with pre-theoretic intuition

\footnotetext{
${ }^{65}$ Saucedo, op. cit., at pp. $269-70$.

${ }^{66}$ See also the argument against "brute necessity" in Cian Dorr, "There Are No Abstract Objects," in John Hawthorne, Theodore Sider, and Dean W Zimmerman, eds., Contemporary Debates in Metaphysics (Oxford: Blackwell, 2008), pp. 32-63, at p. 53.

${ }^{67}$ Sider, "Parthood," op. cit., at pp. 52-3.
} 
weighs heavily with many endurantists. ${ }^{68}$ They should be quite reluctant to endorse such a counterintuitive claim as the denial of AF3.

That completes my defense of the premises of the argument. They are variably plausible, but all at least prima facie compelling. This makes a plausible case for the conclusion of the argument, that endurantism is incorrect. Without good and independent reason to accept the exotic possibilities of crowded simples and their ilk, we should reject endurantism, at least of the sort countenanced here. (And if we plump for some other sort of endurantism, we are left without a response to Sider's anti-endurance argument with which we began.)

One independent reason to accept the falsity of AF3 would be if it turned out that a commitment to the fundamentality of location was incurred by everyone, regardless of their views on persistence. Then modus tollens would be the appropriate response to this argument; we should reject that premise (Saucedo's own response to the argument). In the next section, I will consider whether perdurantists need accept that location is fundamental. I conclude that they need not.

\section{PERDURANCE AND FUNDAMENTAL LOCATION}

Endurantists make use of a fundamental location relation in accounting for the difference between possible persistence scenarios that agree in qualitative facts about regions, as in the example discussed in §IV. Since perdurantists typically reject any such non-supervenience of persistence on the qualities of regions, they have no need of a fundamental location relation for this purpose. However, if there are other motivations for introducing a fundamental location relation, the fact that perdurantist accounts of persistence do not require it will matter little.

\footnotetext{
${ }^{68}$ Judith Jarvis Thomson, "Parthood and Identity Across Time," this JOURNAL, LXXX, 4 (April 1983): 20120, at p. 210.
} 
One such motivation comes from dualism about material objects, the thesis that material objects are distinct from their exact locations. If we endorse dualism, we will need to make use of the exact location relation to specify the relationship between material objects and their locations. A complete enumeration of material objects and their properties, and regions of spacetime and their properties, will still not suffice to specify a possibility unless we know which objects are where. (The obvious strategy of trying to "match up" regions and objects on the basis of their properties will be defeated by possibilities exhibiting various kinds of mirror symmetry.) Dualism about material objects appears to provide good reason to accept fundamental location, even for perdurantists, leaving them equally open to the argument of the previous section.

I have been tacitly assuming dualism so far. But why should a perdurantist feel the pull of dualism in the first place? There is some prima facie plausibility to the idea that material objects are one sort of thing, and regions of spacetime another. Ordinary English suggests dualism to us; our locative talk is pervaded by the presupposition that regions are where events happen, not participants in them. But we are not forced to accept this presupposition. Ordinary English talks of places and times rather than spacetime, yet the spacetime perspective seems metaphysically more illuminating: we have precedent for theoretically motivated revision of our basic locational vocabulary. And the strange possibilities generated by recombination of distinct things and places rather undermine dualism's claim to intuitive plausibility.

The rival to dualism that I suggest deserves our credence is supersubstantivalism, ${ }^{69}$ (or the "identity theory of location" ${ }^{, 70}$ ): the thesis that material objects are - are literally identical to - that region of substantial spacetime which is their unique exact location, so that the exact location

\footnotetext{
${ }^{69}$ Lawrence Sklar, Space, Time, and Spacetime (Berkeley: University of California Press, 1974), at p. 214.

${ }^{70}$ Parsons, op. cit., at p. 227.
} 
relation is the identity relation. ${ }^{71}$ Supersubstantivalism is theoretically attractive for perdurantists, as it achieves a great gain in simplicity with no loss in descriptive adequacy. All the properties apparently had by an occupant of spacetime can be understood as being instantiated by the region of spacetime itself. The facts about the locations of objects for perdurantists already supervene on the qualities of their underlying locations - that is evident already in the standard perdurantist treatment of persistence cases like the one in §IV above. Accordingly, we do away with a redundant ontological category if we simply reduce objects to their locations; the identification of spatiotemporal objects with regions is just crying out to be made. ${ }^{72}$

Having done so, supersubstantivalism provides an easy route to block the anti-fundamentality argument. The kinds of exotic scenarios envisaged in support of AF1 are no longer constructible under supersubstantivalism, because exact location is reducible to parthood and not distinct from it. (Given the assumption that mereology is extensional, $a$ will be exactly located at $R$ iff $a$ and $R$ share all their parts.) The particular construction of a compact fusion given in $\S \mathrm{V}$ is blocked because, given supersubstantivalism, in the scenario $w, a=R$ and $b=S$; so it turns out that $a$ is a proper part of $b$ and vice versa, which is impossible. Since identity is one-one, supersubstantivalism entails that multiple exact location is impossible; since endurance involves multi-location, this way out of the anti-fundamentality argument is not available to the endurantist.

For the perdurantist, objects extend through time and space by having parts at each place in spacetime that they fill. Why should there be this perfect correspondence between the mereological structure of things, and the mereological structure of the largest region they fill? The answer, according to the supersubstantivalist, is that the object is identical to that region,

\footnotetext{
${ }^{71}$ Jonathan Schaffer, "Spacetime the One Substance," Philosophical Studies, CXLV, 1 (July 2009): 131-48; Sider, Four-Dimensionalism, op. cit., at pp. 110-9.

${ }^{72}$ Sider, ibid., at p. 110.
} 
rendering "their" structural harmony unsurprising. Dualist perdurantists cannot avail themselves of this answer; and it is unclear what other explanation of the proliferation of material parts they might give (apart from arguing that it would be helpful if there were many temporal parts in accounting for puzzles about persistence through change).

While historically perdurance emerged as a thesis about the persistence of ordinary objects, further developments of the theory have brought out how little the fundamental ontology of the theory has to do with ordinary objects. The needs of the theory can be satisfactorily met by an ontology that involves just regions of spacetime and their properties, as long as some of the regions turn out to have some qualities that render them "matter-filled" ${ }^{73}$

There remains the interesting question concerning which regions correspond to ordinary objects. It is through addressing this question about the relation between the non-fundamental realm and fundamental ontology that the perdurantist engages with endurantist questions about location and persistence. But there is no interesting issue of ontology here. It is just a matter of figuring out how best to characterize the emergence of ordinary objects from the fundamental ontology; ${ }^{74}$ that is, to figure out whether to classify one or another of the candidate entities of fundamental metaphysics as this or that sort of ordinary object. Doing so of course involves some "bridge principles" which sound odd, or have odd consequences. (Sider gives this example of an odd sounding truth: "A region of spacetime bounded out the door and barked at the mailman". ${ }^{75}$ ) But, when properly translated into the fundamental language, nothing problematic results. ${ }^{76}$

\footnotetext{
${ }^{73}$ Cf. Mark Heller, The Ontology of Physical Objects (Cambridge: Cambridge University Press, 1990).

${ }^{74}$ Frank Jackson, From Metaphysics to Ethics (Oxford: Clarendon Press, 1998), at pp. 1-5.

${ }^{75}$ Sider, Four-Dimensionalism, op. cit., at p. 110.

${ }^{76}$ One issue of some significance concerns the modal properties of regions of spacetime, given that it is possible that ordinary objects have different spatiotemporal extent than they actually have, and yet it is impossible that regions of spacetime have different spatiotemporal extent than they actually have. (See van
} 


\section{CONCLUSION}

I have argued that Sider's argument from vagueness for perdurantism fails, as it involves a premise that can be denied in a principled way by endurantists who accept a multi-locational conception of endurance. Sider does not discuss this response, I assume because he was not thinking of endurance as a thesis about location. (He does not highlight it in his attempts to characterize endurance. ${ }^{77}$ )

But due to its reliance on a fundamental exact location relation, this conception of endurance is subject to another argument, the anti-fundamentality argument. Dualist varieties of perdurance are also subject to this argument. However, there is a natural and principled form of perdurantism, involving an supersubstantivalist theory of material objects and spacetime regions, which is immune to the argument, and has all the virtues in dealing with the paradoxes of change and coincidence that are ordinarily claimed for perdurantism. Perdurantists should, accordingly, embrace this view. Since it is simple and powerful, and involves no revisions to ordinary beliefs that perdurantists are not already inclined to make, I expect many will. Defending supersubstantivalism is not without its challenges, but this paper is not the place to make the broader case for the view. ${ }^{78}$ I only wish to remark that perdurantists often do better by their own lights, given the other revisions of commonsense they apparently have to accept, to accept in addition the simplifying hypotheses of supersubstantivalism.

Inwagen, op. cit.) The orthodox perdurantist answer - required for many other reasons - is to adopt a counterpart theoretic analysis of de re modal predication (Sider, ibid., at pp. 219-24). We may then observe that two different counterpart relations underlie the two true possibility claims in the first sentence of this note. Once this equivocation on de re 'possible' is made explicit, no problem remains - except whatever problems arise for counterpart theory directly.

${ }_{77}$ Sider, Four-Dimensionalism, ibid., at pp. 63-8.

${ }^{78}$ For defenses of supersubstantivalism against the main objections, see Schaffer, op. cit., pp. 144-6, Sider, ibid., at pp. 110-3; and Bradford Skow, Once Upon a Spacetime, PhD thesis (New York: NYU, 2005), pp. 54-71. 
The options for endurantism are less clear. For it now falls to endurantists to offer a characterization of endurance that is subject to neither Sider's nor my argument. I know of no developed account of endurance at present that is able to manage this. However, the sort of nonlocational conceptions of endurance sketched by Hawthorne and Paul seem like good avenues to explore. ${ }^{79}$ I have no clear idea how this exploration will go, but the habitual ingenuity of endurantists suggests some reason for optimism. ${ }^{80}$

\footnotetext{
${ }^{79}$ John Hawthorne, "Three-Dimensionalism vs. Four-Dimensionalism," in Hawthorne et al., eds., op. cit., pp. 263-82; L.A. Paul, "Logical Parts," Noûs, XXXVI, 4 (December 2002): 578-96.

${ }^{80}$ This paper is a distant descendent of a number of earlier and very different drafts. For comments on those earlier versions, my gratitude to audiences at the 2014 Australian Metaphysics Conference, 2010 Carolina Metaphysics Workshop, at a TWiP meeting in Oxford, at the 2009 AAP (my attendance at which was supported by a travel grant from the British Academy), and the Serious Metaphysics Group in Cambridge. Special thanks go to Shamik Dasgupta (my commentator in North Carolina), Sam Baron, Paul Daniels, Cian Dorr, Cody Gilmore, Benj Hellie, Peter van Inwagen, Daniel Nolan, Josh Parsons, Laurie Paul, Olly Pooley, Ted Sider, Alex Skiles, Gabriel Uzquiano, and Jessica Wilson.
} 